LIVER

\title{
Bacterial DNA activates cell mediated immune response and nitric oxide overproduction in peritoneal macrophages from patients with cirrhosis and ascites
}

\author{
R Francés, C Muñoz, P Zapater, F Uceda, I Gascón, S Pascual, M Pérez-Mateo, J Such
}

Gut 2004;53:860-864. doi: 10.1136/gut.2003.027425

See end of article for authors' affiliations

Correspondence to: Dr J Such, Liver Unit, Hospital General Universitario, Pintor Baeza $\mathrm{s} / \mathrm{n}, 03010$ Alicante, Spain; such_jos@gra.es

Accepted for publication 12 November 2003

\begin{abstract}
Background and aims: Translocation of intestinal bacteria to ascitic fluid is probably the first step in the development of episodes of spontaneous bacterial peritonitis in patients with cirrhosis. We have recently reported the detection of bacterial DNA in blood and ascitic fluid from patients with advanced cirrhosis, what we consider as molecular evidence of bacterial translocation. Several studies have shown the immunogenic role of bacterial DNA in vitro, and we hypothesised that the presence of bacterial DNA could activate the type I immune response in peritoneal macrophages from these patients, leading to greater cytokine synthesis (interleukin (IL)-2 and IL-12, tumour necrosis factor $\alpha$, and interferon $\gamma$ ) and effector molecules such as nitric oxide.

Methods: Peritoneal macrophages obtained from patients with cirrhosis and culture negative nonneutrocytic ascitic fluid were collected and characterised by flow cytometry. Inducible nitric oxide synthase, nitric oxide levels, and cytokine production were measured by immunoenzymometric assays in basal and harvested conditions according to the presence/absence of bacterial DNA.

Results: The ability of peritoneal macrophages to synthesise nitric oxide and levels of all cytokines were significantly increased in patients with bacterial DNA. There was a positive correlation between inducible nitric oxide synthase and nitric oxide levels.

Conclusions: The presence of bacterial DNA in patients with decompensated cirrhosis is associated with marked activation of peritoneal macrophages, as evidenced by nitric oxide synthesising ability, together with enhanced cytokine production.
\end{abstract}

B acterial infections are frequently observed complications arising in patients with cirrhosis, and among them, spontaneous bacterial peritonitis (SBP) is probably the most relevant. ${ }^{12}$ SBP probably occurs as a consequence of repeated access of bacteria from the intestinal lumen through a haematogenous route reaching the mesenteric lymph nodes $^{3}{ }^{4}$ and, eventually, gaining access to ascitic fluid (AF) in a process that has been termed bacterial translocation (BT). ${ }^{5}$ Supporting this hypothesis, in a previous work we detected the presence of bacterial DNA (bactDNA) fragments simultaneously in blood and AF in as many as $32 \%$ of patients with advanced cirrhosis and sterile nonneutrocytic $\mathrm{AF}^{6}{ }^{6}$ a fact that we interpret as molecular evidence of BT.

BactDNA includes a repeated series of unmethylated CpG motifs that bind to the toll-like receptor 9, thus becoming a potent activator of cells of the innate immune system, namely macrophages, dendritic cells, and natural killer cells, ${ }^{17}$ and leading to increased synthesis of proinflammatory cytokines and effector molecules. Similarly, CpG motifs stimulate natural killer (NK) cells to synthesise interferon $\gamma($ IFN- $\gamma)$, which in turn enhances the toxicity of other agents such as lipopolysaccharide (LPS $)^{9}$ and prime nitric oxide (NO) synthesis through expression of the inducible form of NO synthase $(\mathrm{iNOS})^{10}$ that has been reported to play an important role in the macrophage mediated response to infectious agents. ${ }^{11} 12$

As we detected the presence of bactDNA in a subgroup of patients with decompensated cirrhosis, we hypothesised that peritoneal macrophages obtained from these patients should be primed for higher NO and cytokine release. Thus the aims of this study were to evaluate the NO synthesising ability, together with the cytokine cascade probably involved in the process, in peritoneal macrophages from our series of patients, according to the presence of bactDNA.

\section{PATIENTS AND METHODS \\ Patients}

Since April 2000, all patients with cirrhosis and culture negative non-neutrocytic AF have been consecutively included in a prospective study in our Liver Unit to detect and identify the presence of bactDNA in blood and/or AF, according to the methodology previously described. ${ }^{6}$ A series of 10 consecutively admitted patients with or without bactDNA in blood and AF were included in the study protocol.

Cirrhosis was diagnosed by histology or by clinical, laboratory, and/or ultrasonographic findings. Exclusion criteria were the presence of culture positive blood or AF, neutrocytic AF ( $\geqslant 250$ polymorphonuclear leucocytes (PMN)/ $\mu \mathrm{l})$, signs or symptoms of systemic inflammatory response syndrome according to previously published criteria, ${ }^{13}$ upper gastrointestinal bleeding or intake of antibiotics in the preceding two weeks, including selective intestinal decontamination with norfloxacin, hepatocellular carcinoma and/or portal thrombosis, alcoholic hepatitis, and refusal to participate in the study. The ethics committee of Hospital General Universitario approved the study protocol and all patients gave informed consent for inclusion in the study.

Abbreviations: SBP, spontaneous bacterial peritonitis; $A F$, ascitic fluid; $\mathrm{BT}$, bacterial translocation; bactDNA, bacterial DNA; NK, natural killer; IFN- $\gamma$, interferon $\gamma$; NO, nitric oxide; iNOS, inducible NO synthase; PMN, polymorphonuclear leucocytes; LPS, lipopolysaccharide; MoAbs, monoclonal antibodies; TNF- $\alpha$, tumour necrosis factor $\alpha$; IL, interleukin 
Blood was obtained for routine haematological, biochemical, and coagulation studies. Simultaneously, large volume paracentesis was performed in all patients on admission under aseptic conditions, following the usual procedures, ${ }^{13}$ and samples for routine biochemical study and PMN count were obtained. Total protein, albumin, leucocyte count, and PMN count were performed on all AF specimens. Both blood and AF were inoculated at the bedside in aerobic and anaerobic blood culture bottles, $10 \mathrm{ml}$ each. ${ }^{14}$ Samples of blood and AF were inoculated in rubber sealed pyrogen free tubes (Endo Tube ET; Chromogenix AB, Vienna, Austria).

\section{Peritoneal macrophages culture}

A volume of $800-1500 \mathrm{ml}$ of AF, collected after therapeutic paracentesis, was centrifuged at $1500 \mathrm{~g}$ for 10 minutes to obtain the cellular pellet. After washing with phosphate buffer saline (PBS) three times, more than $80 \%$ of the macrophage population was counted from a total number of 10-16 million cells, in all cases using Testsimplets prestained slides (Roche Diagnostics Ltd, Sussex, UK). Cell viability was also evaluated by trypan blue (Sigma, Madrid, Spain) and resulted in more than $95 \%$ viability. Cells $\left(4 \times 10^{6}\right)$ were separated for macrophage characterisation by flow cytometry; $1 \times 10^{6}$ cells were prepared to obtain the cell lysates for iNOS quantification according to the manufacturer's instructions and $5 \times 10^{6}$ macrophages were resuspended in $5 \mathrm{ml}$ of phenol red free RPMI 1640 medium (Gibco BRL, Life Technologies, Paisley, UK) supplemented with 10\% human serum AB (BioWhittaker, Walkersville, Maryland, USA), $100 \mathrm{IU} / \mathrm{ml}$ penicillin/streptomycin, and $2.5 \mu \mathrm{g} / \mathrm{ml}$ amphotericin B (Gibco BRL). Macrophages $\left(2 \times 10^{6}\right)$ were incubated as controls, and $2 \times 10^{6}$ macrophages were cultured adding $0.2 \mu \mathrm{g}$ of LPS from $E$ coli serotype 0111:B4 (Sigma) in a 24 well plate for 24 hours at $37^{\circ} \mathrm{C}$ in a humidified atmosphere with $5 \% \mathrm{CO}_{2}$. Supernatants were obtained by centrifugation at $2500 \mathrm{~g}$ for five minutes and stored at $-80^{\circ} \mathrm{C}$ until assay. The maximum period of time between being frozen and thawing was three months and in the current study none of the specimens was thawed and refrozen prior to analysis.

\section{Immunostaining of cell surface and characterisation of the monocyte/macrophage population}

At the indicated time of culture, cells were harvested and washed once in ice cold PBS, suspended in $500 \mu \mathrm{l}$ of PBS, and distributed $(50 \mu \mathrm{l}$ per tube) to polystyrene round bottom tubes (Becton Dickinson, San Diego, California, USA) for immunolabelling. Surface determinant immunostaining was performed with unfixed cells using fluorochrome conjugated monoclonal antibodies (MoAbs) against the surface determinants. The combinations CD45 PerCP/CD3 FITC, CD45 PerCP/ CD33 PE, CD45 PerCP/CD14 FITC, and CD14 FITC/CD33 PE were added for better discrimination between monocytes and lymphocytes in AF mononuclear cells during flow cytometry analysis. Cells were incubated in the dark for 15 minutes, washed in cold PBS, fixed, and permeabilised with IntraPrep permeabilisation reagent (Immunotech Beckman Coulter, Marseille, France). Then, cells were washed in PBS and stained (30 minutes in the dark) for intracellular cytokines using FITC conjugated MoAbs against tumour necrosis factor $\alpha$ (TNF- $\alpha$ ) and interleukin (IL)-6, and PE conjugated MoAbs against IL- 8 and IL-1- $\beta$. FITC and PE conjugated isotype controls were used in parallel. After cells were washed in PBS they were suspended with paraformaldehyde $1 \%$ in PBS for flow cytometry analysis. Samples were analysed in a FACS sort flow cytometer (Becton Dickinson, Immunocytometry Systems, Palo Alto, California, USA) using Cellquest (version 3.2 ) software. Typically, list mode data for 20000 events for $\mathrm{CD}^{+} 5^{+}$cells in a "live gate" mode were acquired.

\section{Measurement of NO production and human iNOS levels}

The sum of the NO metabolites nitrite $\left(\mathrm{NO}_{2}{ }^{-}\right)$and nitrate $\left(\mathrm{NO}_{3}{ }^{-}\right)$is widely used as an index of $\mathrm{NO}$ generation and expressed as NOx levels per ml, which corresponds to $10^{6}$ cells in this study. NOx levels in basal AF, and in supernatants from cultured macrophages, were calculated by measuring conversion of $\mathrm{NO}_{3}{ }^{-}$to $\mathrm{NO}_{2}{ }^{-}$by the enzyme nitrate reductase using an ELISA assay ( $R \& D$ Systems, Minneapolis, USA) based on the Griess reaction that absorbs visible light at $540 \mathrm{~nm}$. All samples were tested in duplicate and values were corrected by running samples with culture media without macrophages to assess background NOx levels. Quantitative determination of iNOS concentrations was performed through the Quantikine Human iNOS Immunoassay (R\&D Systems) in cell lysates, obtained according to the manufacturer's instructions and expressed as $\mathrm{U} / \mathrm{ml}$.

\section{Measurement of IFN- $\gamma$, TNF- $\alpha$, IL-2, and IL- 12}

Immunoenzymometric assays for quantitative measurement of human IFN- $\gamma$, TNF- $\alpha$, IL-12, and IL-2 in AF samples were performed by handling Biosource IFN- $\gamma$ EASIA kit (Biosource Europe SA, Nivelles, Belgium), human TNF- $\alpha$ HS Quantikine, and IL-12 and IL-2 Quantikine (R\&D Systems) according to the manufacturer's instructions. All samples were tested in duplicate and read at $450 \mathrm{~nm}$ and $490 \mathrm{~nm}$ in a ThermoMax microplate reader (Molecular Devices, Sunnyvale, California, USA).

\section{Statistical analysis of experimental data}

All observations are reported as mean (SD). Statistical differences in basal characteristics between groups were analysed using the $\chi^{2}$ test for categorical data applying Yates' correction when required, the Mann-Whitney $U$ test for quantitative data without a normal distribution according to the Komolgorov-Smirnov test, and the Student's $t$ test for variables with a normal distribution. The ANOVA test with the post hoc Tukey test was used for multiple comparisons. Bivariate correlations were evaluated using the Pearson test. All $\mathrm{p}$ values were two tailed. A p value $<0.05$ indicated statistical significance. Analyses were performed with the SPSS statistical package (SPSS Inc. version 11.0, Chicago, Illinois, USA).

\section{RESULTS \\ Characteristics of patients and laboratory data}

All patients fulfilling the inclusion and exclusion criteria were considered for entry into the study. Ten consecutively admitted patients in whom we did not detect or detected the presence of bactDNA comprised groups I and II, respectively. Clinical and analytical characteristics of the patients in both groups at admission are shown in table 1. No significant differences were observed in any of the parameters between the two groups of patients.

BactDNA was always detected simultaneously in blood and AF. Similarity in sequences between blood and AF was more than $99.5 \%$ in all cases, and identifications obtained from the NCBI Database by the advanced BLAST search ${ }^{15}$ included E coli $(\mathrm{n}=7)$, Klebsiella $(\mathrm{n}=2)$, and $S$ aureus $(\mathrm{n}=1)$.

Upper gastrointestinal endoscopy was performed at the index admission or in the preceding three months in eight patients in group I and in seven patients in group II. No differences were observed in the presence or size of oesophageal varices or in portal hypertensive gastropathy between the two groups of patients.

Patients were followed up during admission from inclusion in this study. Two patients from group II died during admission; one from terminal liver failure and one from 
Table 1 Basic clinical and analytical characteristics of the cohort distributed according to the absence (group I) or presence (group II) of bacterial DNA in serum and ascitic fluid

\begin{tabular}{lcc}
\hline & Group I $(\mathbf{n}=10)$ & Group II ( $\mathbf{n}=10)$ \\
\hline Mean age (y) & $65(10)$ & $65(12)$ \\
Sex (M/F) & $9 / 1$ & $8 / 2$ \\
Aetiology (n) & 10 & 10 \\
Alcohol & 9 & 6 \\
HCV & 0 & 2 \\
Alcohol+HCV & 0 & 1 \\
Other & 1 & $9 / 1$ \\
Diuretics (yes/no) & $9 / 1$ & $8.89(1.19)$ \\
Child Pugh (mean score) & $8.63(1.27)$ & $2.5(1.2)$ \\
Bilirubin (mg/dl) & $2.6(1.6)$ & $2.5(0.5)$ \\
Albumin (g/dl) & $2.8(0.8)$ & $59.4(15.1)$ \\
Quick (\%) & $64.1(15.9)$ & $6520(3034)$ \\
WBC/mm & $6351(2172)$ & $1.6(0.5)$ \\
AF total protein (g/dl) & $1.9(0.9)$ & $106(67)$ \\
AF WBC/mm & $15.2(26.3)$ \\
\% AF PMNs & $248(267)$ & \\
\hline & $14.9(15.1)$ & \\
Data are mean (SD). & \\
WBC, white blood cell, AF, ascitic fluid; HCV, hepatitis C virus; PMN, polymorphonuclear leucocytes. \\
No significant differences between the two groups.
\end{tabular}

acute pancreatitis. One patient in group I developed culture negative spontaneous bacterial peritonitis and one patient in group II developed a vertebral abscess. Infections developed seven and 12 days, respectively, after the initial paracentesis.

\section{Gating of monocyte population and production of intracellular cytokines}

Monocyte populations were defined on the basis of cell granularity and fluorochrome conjugated MoAbs CDI4-FITC and CD33-PE (fig 1). No differences between groups were found in an ANOVA test, with the stimuli and MoAbs as factors in the analysis. The average monocyte population activated was 76.1 (SD 14.7)\%.

\section{AF NOx and cytokine levels}

Basal AF NOx levels in patients from group II were higher than those observed in patients from group I although values did not reach statistical significance, probably due to the reduced number of cases (table 2). NOx levels measured in the supernatant of non-stimulated macrophages from patients in group II were significantly higher than those observed in patients in group I. Furthermore, addition of cellular stimulants to the culture media induced a marked increase in NOx levels in both groups of patients but values only reached significance in patients in group I (table 2).
Basal values of all four cytokines were significantly higher in patients in group II than in patients in group I. Values obtained in the supernatant of non-stimulated cultures were significantly higher in patients in group II than in patients in group I, with the exception of IFN- $\gamma$. However, we did not observe significant differences for any of the cytokines in the supernatant of stimulated cultures between groups. Addition of LPS to cultures induced a significant increase in all cytokines in comparison with values observed without stimulation in both groups of patients (table 2).

Although the limited number of bacteria isolated (seven $E$ coli, two K pneumoniae, one $S$ aureus) precludes any statistical analysis, we did not observe any difference in the immune response according to the type of bacteria detected in patients in group II.

\section{Human iNOS concentrations in cell lysates}

Relative mass values for naturally occurring iNOS under all three experimental conditions are detailed in table 2 . Statistically significant differences were observed between values obtained at baseline and in non-stimulated cultures between both groups of patients. Addition of LPS to the culture medium induced a significant increase in iNOS concentration compared with samples obtained without stimulation in both groups of patients (table 2).
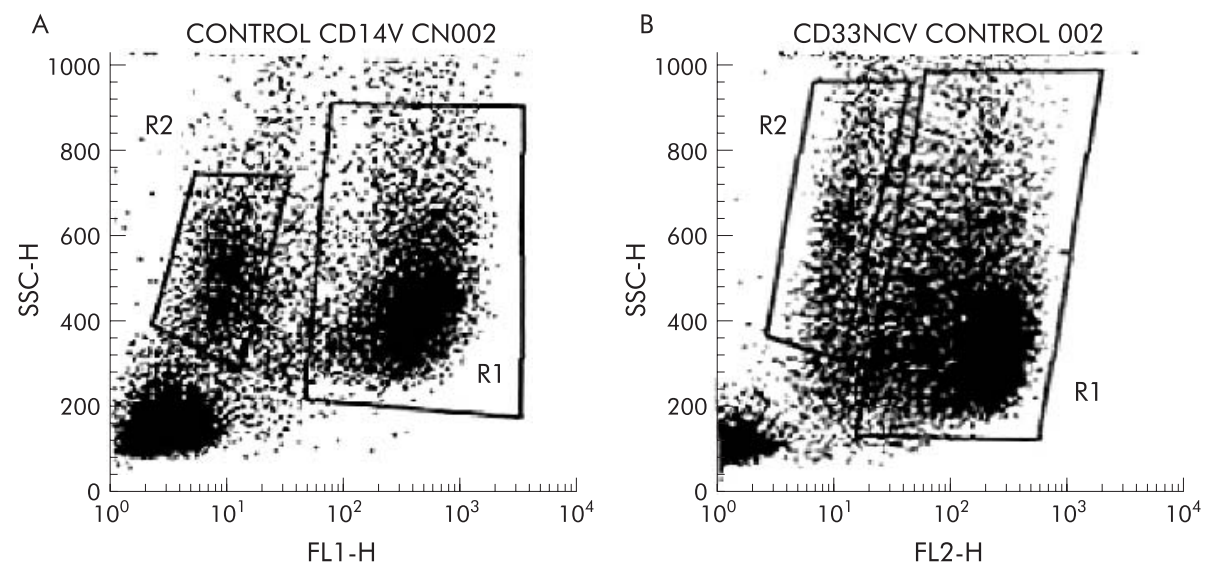

Figure 1 Gating of the monocyte population. Monocyte populations were defined on the basis of cell granularity (SSC-H) and the fluorochrome conjugated monoclonal antibodies anti-CD33-PE (FL2-H) and anti-CD14-FITC (FLH-1). Regions R1 and R2 correspond to monocytes and polymorphonuclear cells, respectively. 
Table 2 NOx, TNF- $\alpha$, IFN- $\gamma$, and IL-12 levels in ascitic fluid in patients in groups I and II

\begin{tabular}{|c|c|c|c|c|c|c|}
\hline & NOx (nmol/ $10^{6}$ cells) & iNOS (U/10 cells) & TNF- $\alpha$ (pg/10 cells) & IFN- $\gamma\left(\mathrm{nmol} / 10^{6}\right.$ cells $)$ & IL-2 (pg/ $10^{6}$ cells) & IL-12 (pg/ $10^{6}$ cells) \\
\hline \multicolumn{7}{|l|}{ Group I } \\
\hline Basal & $21.2(13.0)$ & $4.5(3.1)$ & $15.6(4.4)$ & $26.9(5.8)$ & $22.1(6.0)$ & 9.1 (1.7) \\
\hline $24 \mathrm{~h}$ & $57.5(22.4)$ & $7.5(3.9)$ & $21.9(9.3)$ & $31.0(6.1)$ & $29.3(7.1)$ & $12.5(6.0)$ \\
\hline $24 h+$ LPS & $85.6(26.9) \dagger$ & $24.2(10.3) \dagger$ & $57.6(5.6) \dagger$ & $52.7(5.7) \dagger$ & $61.0(10.3) \dagger$ & $76.0(9.7) \dagger$ \\
\hline \multicolumn{7}{|l|}{ Group II } \\
\hline Basal & $35.6(20.8)$ & $13.2(4.5)^{\star}$ & $35.3(17.7)^{*}$ & $40.2(8.0)^{*}$ & $62.1(10.3)^{\star}$ & $71.7(7.8)^{*}$ \\
\hline $24 \mathrm{~h}$ & $93.2(35.6)^{*}$ & $17.1(5.1)^{*}$ & $46.0(9.0)^{*}$ & $46.1(8.8)$ & $68.0(10.3)^{*}$ & $80.3(6.9)^{*}$ \\
\hline $24 \mathrm{~h}+\mathrm{LPS}$ & $122.3(44.5)^{*}$ & $28.6(7.7) \dagger$ & $63.2(10.2) \dagger$ & $55.4(8.2) \dagger$ & $74.1(9.0) \dagger$ & $90.6(9.5) \dagger$ \\
\hline $\begin{array}{l}\text { Data are me } \\
\text { NOx, sum of } \\
\text { iNOS, induci } \\
\text { Basal, ascitic } \\
24 \text { hours with } \\
{ }^{*} p<0.05 \text { ver }\end{array}$ & $\begin{array}{l}\text { metabolites, nitrite ano } \\
\text { nitric oxide synthase. } \\
\text { amples obtained at adn } \\
\text { f lipopolysaccharide (L } \\
\text { esponding value in gro }\end{array}$ & $\begin{array}{l}\text { nitrate; TNF- } \alpha \text {, tum } \\
\text { mission; } 24 \mathrm{~h} \text {, supern } \\
\text { PS) to the culture mec } \\
\text { up I; } \dagger p<0.05 \text { versu }\end{array}$ & $\begin{array}{l}\text { atant of culture afte } \\
\text { dium. } \\
\text { s the corresponding }\end{array}$ & hours without stimul & $\begin{array}{l}\text { I IL-12, interleukin } 2 \\
\text { on; } 24 \text { h+LPS, supern } \\
\text { t stimulation. }\end{array}$ & $\begin{array}{l}\text { and } 12 \text {, respectively; } \\
\text { atant of culture affer }\end{array}$ \\
\hline
\end{tabular}

A direct and significant correlation was found between basal iNOS and NOx levels in the overall group of patients $\left(r^{2}=0.72, p=0.03\right)$ (fig 2$)$ and also between basal values of iNOS and all cytokines studied, with the exception of TNF- $\alpha$ $\left(\right.$ IFN- $\gamma r^{2}=0.77, \mathrm{p}=0.04 ;$ TNF- $\alpha r^{2}=0.65, \mathrm{p}=0.09 ;$ IL- 12 $r^{2}=0.79, \mathrm{p}=0.001$; IL-2 $\left.r^{2}=0.84, \mathrm{p}=0.001\right)$.

\section{DISCUSSION}

In this study, we have shown that peritoneal macrophages, obtained from patients with cirrhosis and AF, and the presence of bactDNA are primed to synthesise significantly higher amounts of NO than macrophages obtained from patients without bactDNA, and this is associated with marked activation of the cytokines implicated in the type 1 immune response.

Bacterial infections are common complications in patients with advanced cirrhosis, and SBP is the most frequent and clinically relevant. ${ }^{1}$ The classical pathogenic theory of SBP suggests that bacteria of intestinal origin move across the intestinal wall, ${ }^{5}$ reaching mesenteric lymph nodes and other organs. Bacteria can then obtain access to AF, and a SBP episode may eventually develop if the local bactericidal mechanisms are insufficient to mount an adequate response. ${ }^{16}{ }^{17}$

We have recently described the presence of bactDNA in patients with cirrhosis and culture negative non-neutrocytic $\mathrm{AF}$, a fact that we interpret as molecular evidence of BT. ${ }^{6}$ It is likely that bacteria reaching AF may activate the cellular component of the innate immune system, modifying its

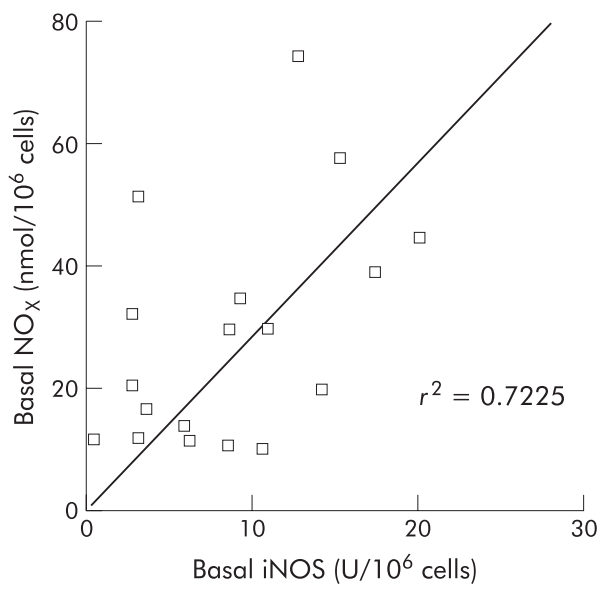

Figure 2 Correlation between basal inducible NO synthase (iNOS) and NOx (sum of nitric oxide metabolites, nitrite and nitrate) levels in peritoneal macrophages obtained from ascitic fluid in patients with decompensated cirrhosis. inflammatory response and NO synthesising ability, a situation similar to what has been described in in vitro models. ${ }^{918}$ Thus the aim of this study was to assess the macrophage immune response according to the presence or absence of bactDNA in patients with cirrhosis.

BactDNA is characterised by the presence of short repeated sequences of unmethylated $\mathrm{CpG}$ dinucleotides. Different experimental studies have shown the immunomodulatory role of these fragments, capable of inducing a similar immune response to that produced by a complete microorganism in vitro, ${ }^{19-21}$ thus becoming potent activators of cells of the innate immune system (namely, NK, macrophages, and dendritic cells) by binding toll-like receptor 9.7

BactDNA mediated macrophage activation leads to TNF- $\alpha$, IL-6, and IL-12 synthesis. ${ }^{20}{ }^{22}$ These last two cytokines activate $\mathrm{B}$ and $\mathrm{T}$ cells ${ }^{2324}$ and modulate IFN- $\gamma$ production by contributing to NK cell activation in vivo and in vitro. ${ }^{85}{ }^{26}$ As IFN- $\gamma$ receptors are also expressed on the macrophage surface, the presence of increased levels of IFN- $\gamma$ further enhances TNF- $\alpha$ production and upregulates the transcription of the iNOS gene 7-32 $^{27}$ leading to an increase in macrophage NO synthesising capability.

Peritoneal macrophages from cirrhotic patients with ascites and a previous episode of SBP have been shown to be activated, with NO overproduction, ${ }^{33}$ a situation similar to that described here, as suggested by the fact that NOx levels were higher in patients with molecular evidence of BT (group II) compared with patients in group I (table 2). Also, the existence of a direct and significant correlation between iNOS and NOx levels strongly suggests that NOx detected in the supernatant of cultures of peritoneal macrophages is iNOS derived. One of the best described functions of iNOS is its role in the macrophage mediated response to infectious agents. ${ }^{11}{ }^{12}$ Furthermore, iNOS produces physiological concentrations of NO in the nanomolar range. ${ }^{34}$ Micromolar concentrations observed in our study are consistent with these data, considering overactivation of macrophages in response to bacterial DNA.

As described previously, the increase in NO synthesis is not an isolated phenomenon but a consequence of a complex sequence of events in which several cytokines play a significant role. In fact, $\mathrm{NO}$ has been shown to downregulate cytokine release from macrophages. ${ }^{35}$ Supporting this, the reported differences in the ability of macrophages to synthesise NO is associated with a marked inflammatory scenario. We observed significant basal differences in all four cytokines evaluated (table 2) between both groups of patients, which indicates two clearly differentiated populations according to the absence (group I) or presence (group II) of bactDNA.

We observed a positive correlation between IL-2, IL-12, and IFN- $\gamma$ and iNOS values, and the cytokine dependent 
induction of iNOS has been reported previously. ${ }^{36}$ Elevated production of IFN $-\gamma$ by CpG DNA activated NK cells is mediated by IL- $12^{37}$ and, in fact, we observed a significant correlation between basal levels of these two cytokines, which clearly suggests activation of a type I immune response in these patients. Supporting this assumption, TNF- $\alpha$, which is directly synthesised by macrophages and also enhanced by IFN- $\gamma$, was significantly higher in patients in group II compared with group I.

In summary, peritoneal macrophages from patients with cirrhosis and ascites and the presence of bactDNA are primed for higher cytokine and NO synthesis. Our data suggest identification of a new subset of patients, with a marked preactivation of the cellular component of the immune system, probably in response to the immunogenicity of $\mathrm{CpG}$ motifs present in bactDNA.

\section{ACKNOWLEDGMENTS}

Parts of this work were supported by an unrestricted grant from Schering Plough, and grants GV00-070-12 from Conselleria de Cultura, Generalitat Valenciana, PI 021291 from Fondo de Investigaciones Sanitarias, and Instituto de Salud Carlos III (C03/ 02), Spain.

\section{Authors' affiliations \\ R Francés, C Muñoz, Department of Immunology, Hospital General Universitario, Pintor Baeza s/n, Alicante, Spain \\ P Zapater, Department of Clinical Pharmacology, Hospital General Universitario, Pintor Baeza s/n, Alicante, Spain \\ F Uceda, I Gascón, S Pascual, M Pérez-Mateo, J Such, Liver Unit, Hospital General Universitario, Pinto Baeza s/n, Alicante, Spain}

\section{REFERENCES}

1 Fernandez J, Navasa M, Gomez J, et al. Bacterial infections in cirrhosis: epidemiological changes with invasive procedures and norfloxacin prophylaxis. Hepatology 2002;35:140-8.

2 Such J, Runyon BA. Spontaneous bacterial peritonitis. Clin Infect Dis 1998:27:669-74.

3 Guarner C, Runyon BA, Young S, et al. Intestinal bacterial overgrowth and bacterial translocation in cirrhotic rats with ascites. J Hepatol 1997;26:1372-8

4 Cirera I, Baver TM, Navasa $M$, et al. Bacterial translocation of enteric organisms in patients with cirrhosis. J Hepatol 2001;34:32-7.

5 Berg RD. Bacterial translocation from the gastrointestinal tract. J Med 1992;23:217-44.

6 Such J, Frances R, Munoz C, et al. Detection and identification of bacteria DNA in patients with cirrhosis and culture-negative, nonneutrocytic ascites. Hepatology 2002;36:135-41.

7 Wagner $\mathrm{H}$. Interactions between bacterial CpG-DNA and TLR9 bridge innate and adaptive immunity. Curr Opin Microbiol 2002;5:62-9

8 Cowdery JS, Chace JH, Yi AK, et al. Bacterial DNA induces NK cells to produce IFN-gamma in vivo and increases the toxicity of lipopolysaccharides. $J$ Immunol 1996; 156:4570-5.

9 Sweet MJ, Stacey KJ, Kakuda DK, et al. IFN-gamma primes macrophage responses to bacterial DNA. J Interferon Cytokine Res 1998;18:263-71.

10 Gao JJ, Zuvanich EG, Xue Q, et al. Cutting edge: bacterial DNA and LPS act in synergy in inducing nitric oxide production in RAW 264.7 macrophages. $\mathrm{J}$ Immunol 1999;163:4095-9.

11 Fang FC. Perspectives series: host/pathogen interactions. Mechanisms of nitric oxide-related antimicrobial activity. J Clin Invest 1997;99:2818-25.
12 Nathan C. Inducible nitric oxide synthase: what difference does it make? J Clin Invest 1997;100:2417-23.

13 Runyon BA. Low-protein-concentration ascitic fluid is predisposed to spontaneous bacterial peritonitis. Gastroenterology 1986:91:1343-6.

14 Runyon BA, Canawati HN, Akriviadis EA. Optimization of ascitic fluid culture technique. Gastroenterology 1988;95:1351-5.

15 Altschul SF, Madden TL, Schaffer AA, et al. Gapped BLAST and PSI-BLAST: a new generation of protein database search programs. Nucleic Acids Res 1997; 25:3389-402.

16 Runyon BA. Patients with deficient ascitic fluid opsonic activity are predisposed to spontaneous bacterial peritonitis. Hepatology 1988;8:632-5.

17 Such J, Guarner C, Enriquez J, et al. Low C3 in cirrhotic ascites predisposes to spontaneous bacterial peritonitis. J Hepatol 1988;6:80-4.

18 Stacey KJ, Sweet MJ, Hume DA. Macrophages ingest and are activated by bacterial DNA. J Immunol 1996;157:2116-22.

19 Klinman DM, Yi AK, Beaucage SL, et al. CpG motifs present in bacteria DNA rapidly induce lymphocytes to secrete interleukin 6 , interleukin 12, and interferon gamma. Proc Natl Acad Sci U S A 1996;93:2879-83.

20 Lipford GB, Sparwasser T, Baver M, et al. Immunostimulatory DNA sequence-dependent production of potentially harmful or useful cytokines. Eur J Immunol 1997;27:3420-6.

21 Yamamoto S, Yamamoto T, Kataoka T, et al. Unique palindromic sequences in synthetic oligonucleotides are required to induce IFNand augment IFNmediated natural killer activity. J Immunol 1992;148:4072-6.

22 Sparwasser T, Miethke T, Lipford G, et al. Macrophages sense pathogens via DNA motifs: induction of tumor necrosis factor-alpha-mediated shock. Eur J Immunol 1997;27:1671-9.

23 Hirano T, Akira S, Taga T, et al. Biological and clinical aspects of interleukin 6. Immunol Today 1990;11:443-9.

24 Le JM, Vilcek J. Interleukin 6: a multifunctional cytokine regulating immune reactions and the acute phase protein response. Lab Invest 1989;61:588-602.

25 Manetti R, Gerosa F, Giudizi MG, et al. Interleukin 12 induces stable priming for interferon gamma (IFN-gamma) production during differentiation of human T helper (Th) cells and transient IFN-gamma production in established Th2 cell clones. J Exp Med 1994;179:1273-83.

26 Trinchieri G. Interleukin-12: a cytokine produced by antigen-presenting cells with immunoregulatory functions in the generation of T-helper cells type 1 and cytotoxic lymphocytes. Blood 1994:84:4008-27.

27 Bories PN, Campillo B, Scherman E. Up-regulation of nitric oxide production by interferon-gamma in cultured peritoneal macrophages from patients with cirrhosis. Clin Sci (Lond) 1999;97:399-406.

28 Gao J, Morrison DC, Parmely TJ, et al. An interferon-gamma-activated site (GAS) is necessary for full expression of the mouse iNOS gene in response to interferon-gamma and lipopolysaccharide. J Biol Chem 1997;272:1226-30.

29 MacMicking J, Xie QW, Nathan C. Nitric oxide and macrophage function. Annu Rev Immunol 1997; 15:323-50.

30 Morales-Ruiz M, Jimenez W, Ros J, et al. Nitric oxide production by peritoneal macrophages of cirrhotic rats: a host response against bacterial peritonitis. Gastroenterology 1997; 112:2056-64.

31 Nussler AK, Di Silvio M, Billiar TR, et al. Stimulation of the nitric oxide synthase pathway in human hepatocytes by cytokines and endotoxin. J Exp Med 1992;176:261-4.

32 Nussler AK, Billiar TR. Inflammation, immunoregulation, and inducible nitric oxide synthase. J Leukoc Biol 1993;54:171-8.

33 Jimenez W, Ros J, Morales-Ruiz M, et al. Nitric oxide production and inducible nitric oxide synthase expression in peritoneal macrophages of cirrhotic patients. Hepatology 1999;30:670-6.

34 Anggard E. Nitric oxide: mediator, murderer, and medicine. Lancet 1994;343:1199-206.

35 Obermeier F, Gross V, Scholmerich J, et al. Interleukin-1 production by mouse macrophages is regulated in a feedback fashion by nitric oxide. J Leukoc Biol 1999;66:829-36.

36 Titheradge MA. Nitric oxide in septic shock. Biochim Biophys Acta 1999; 1411:437-55.

37 Chace JH, Hooker NA, Mildenstein KL, et al. Bacterial DNA-induced NK cell IFN-gamma production is dependent on macrophage secretion of IL-12. Clin Immunol Immunopathol 1997;84:185-93. 


\section{PostScript}

LETTERS

\section{Genetic association between EPHX 1 and Crohn's disease: population stratification, genotyping error, or random chance?}

We read with interest the article by de Jong and colleagues (Gut 2003;52:547-51) reporting studies of genetic associations between DNA polymorphisms in xenobiotic metabolising genes and Crohn's disease (CD). The authors employed a case control study design to test seven polymorphisms in five candidate genes for disease association. Evidence was found for a significant association of a single nucleotide polymorphism (SNP), Tyrl13His $(348 \mathrm{~T}>\mathrm{C})$, in the microsomal epoxide hydrolase l gene (EPHXI), with CD. Homozygosity for the T (Tyr 113) allele was significantly higher in cases than in healthy controls $\left(\chi^{2}=23.7, \mathrm{p}<0.0001\right.$, odds ratio 2.9$)$. The observed frequency of the $\mathrm{T}$ allele in controls was $41 \%$, which is outside the range of frequencies $(58-94 \%)$ reported in other control populations (reviewed in de Jong et al). Its frequency in CD cases was $67 \%$. In view of the strength of reported association, we sought to replicate this observation. We genotyped the Tyrl13His SNP (ref SNP ID rs 1051740) in 307 independent sporadically ascertained cases of CD and 344 ethnically matched healthy control subjects. ${ }^{1}$ This compared with 151 cases and 149 controls typed by de Jong et al. Our study design provided $80 \%$ power to detect a significant difference $(p<0.05)$ in allele frequency of $\geqslant 7.5 \%$ between cases and controls compared with the difference of $26 \%$ observed in the published study. Our power calculations were based on an observed minor (C) allele frequency of $30.2 \%$ in our control cohort, the common ( $\mathrm{T}$ ) allele frequency being $69.8 \%$.

We used TaqMan chemistry (Applied Biosystems) to genotype DNA from cases and controls with an Applied Biosystems 7700 Sequence Detection System. Preoptimised primers and fluorescent probes were obtained from Applied Biosystems (SNP assay ID C 14938 1). All cases and controls were previously genotyped for three confirmed disease susceptibility alleles for $\mathrm{CD}$ (R702W, G908R, Ll007fs) in CARD15, ${ }^{2-4}$ permitting stratification of data by CARD15 mutational status to identify potential gene-gene interactions. ${ }^{5}$ Allele and genotype frequencies were compared between cases and controls using a $\chi^{2}$ test for difference in proportions. Likewise, a $\chi^{2}$ test was used to assess Hardy-Weinberg equilibrium (HWE) across genotypes.

We found no significant differences in allele or genotype frequencies between cases and controls (table 1). Stratification of the data by CARD15 mutation status showed no significant differences in Tyrl13His allele frequencies in $\mathrm{CD}$ cases with none, one, or two CARD15 mutations. Genotypes in our cases and controls were in HWE $(\mathrm{p}>0.5)$.

Case control based studies of genetic association assume that differences in allele frequencies relate directly to the phenotype under investigation, and that no unobserved confounding factors exist which may be attributable to the associated allele. While having greater power than family based studies to detect associations through linkage disequilibrium mapping, case control analysis is susceptible to type I errors (false positives). ${ }^{6}$ One of the most commonly cited explanations for non-replication of genetic associations is stratification, through population admixture, and variability in disease frequencies between and within component subpopulations. However, relatively few instances of this have been clearly established. Stratification may be identified and potentially controlled for by incorporating anonymous genetic markers into the study design. ${ }^{78}$ However, the efficacy of this approach depends on the level of stratification present, and the difference in SNP frequency and disease prevalence in the normal and affected populations. We noted that in de Jong et al the distribution of genotypes in controls for SNP Tyr113His was not in HWE $\left(\chi^{2}=5.67, p=0.017\right)$. It is possible that this may have generated a type I error in their analysis. A degree of population admixture in their control cohort could account for the deviation from HWE and give rise to the observed association between the normally common $\mathrm{T}$ allele (as we observed) and Crohn's disease. Alternative explanations are genotyping error and random chance. We examined the genotype distribution for the seven SNPs tested by de Jong et al and found that in addition to Tyrl13His, the Ile462Val (1506A/G) SNP in CYPlAl was not in HWE $\left(\chi^{2}=7.87, p=0.005\right)$. A recent review of published association studies by $\mathrm{Xu}$ and colleagues ${ }^{9}$ found that $12 \%$ of SNPs tested were inconsistent with HWE in control subjects.

Our findings highlight the value of testing genetic association data for normal genotype distribution, and for rigorous replication of genetic associations with adequate statistical power.

A P Cuthbert, S A Fisher, C M Lewis, C G Mathew

Division of Genetics and Development, Guy's, King's, and St Thomas' School of Medicine, King's College London, Guy's Hospital, London SEl 9RT, UK

J Sanderson

Department of Gastroenterology, St Thomas' Hospital, London SEI 7EH, UK

A Forbes

St Mark's Hospital, Northwick Park, Watford Rd, Harrow, Middlesex HAl 3UJ, UK

Correspondence to: Professor C G Mathew, Department of Medical and Molecular Genetics, GKT School of Medicine, 8th floor Guy's Tower, London SE1 9RT, UK; christopher.mathew@kcl.ac.uk

\section{References}

1 Cuthbert AP, Fisher SA, Mirza MM, et al. The contribution of NOD2 gene mutations to the risk and site of disease in inflammatory bowel disease. Gastroenterology 2002;122:867-74.

2 Ogura Y, Bonen DK, Inohara N, et al. A frameshift mutation in NOD2 associated with susceptibility to Crohn's disease. Nature 2001:411:603-6.

3 Hugot JP, Chamaillard $M$, Zouali $\mathrm{H}$, et al. Association of NOD2 leucine-rich repeat variants with susceptibility to Crohn's disease. Nature 2001;411:599-603.

4 Hampe J, Cuthbert A, Croucher PJ, et al. Association between insertion mutation in NOD2 gene and Crohn's disease in German and British populations. Lancet $2001 ; 357: 1925-8$.

5 Mirza MM, Fisher SA, King K, et al. Genetic evidence for interaction of the $5 \mathrm{q} 31$ cytokine locus and the CARD1 5 gene in Crohn disease. Am J Hum Genet 2003;72:1018-22.

6 Cardon LR, Palmer U. Population stratification and spurious allelic association. Lancet 2003;361:598-604.

7 Pritchard JK, Rosenberg NA. Use of unlinked genetic markers to detect population stratification in association studies. Am J Hum Genet 1999;65:220-8

8 Hoggart CJ, Parra EJ, Shriver MD, et al. Control of confounding of genetic associations in stratified populations. Am J Hum Genet 2003:72:1492-504.

9 Xu J, Turner A, Little J, et al. Positive results in association studies are associated with departure from Hardy-Weinberg equilibrium: hint for genotyping error? Hum Genet 2002;111:573-4.

Table 1 Allele and genotype frequencies between cases and controls

\begin{tabular}{llllllll}
\hline & & \multicolumn{5}{c}{ Tyr113His genotype } & \\
\cline { 5 - 6 } \cline { 5 - 6 } Phenotype & & & $\begin{array}{l}\text { T/T } \\
\text { Tyr/Tyr }\end{array}$ & $\begin{array}{l}\text { T/C } \\
\text { Tyr/His }\end{array}$ & $\begin{array}{l}\text { C/C } \\
\text { His/His }\end{array}$ & $\begin{array}{l}\text { Tyr allele } \\
\text { frequency (T) }\end{array}$ \\
\hline Controls & & 344 & 167 & 146 & 31 & $69.8 \%$ \\
CD & ALL & 307 & 155 & 127 & 25 & $71.2 \%$ \\
CD & O CARD15 DSAs & 202 & 99 & 83 & 20 & $69.6 \%$ \\
CD & 1 CARD15 DSA & 69 & 33 & 33 & 3 & $71.7 \%$ \\
CD & 2 CARD15 DSAs & 20 & 12 & 7 & 1 & $77.5 \%$
\end{tabular}

DSAs, disease susceptibility alleles; CD, Crohn's disease.

\section{Use of cyclosporin in pregnancy}

Cyclosporin has been established in the management of steroid resistant severe ulcerative colitis. We read the letter by Dor and Blanshard (Gut 2003;52:1070) regarding the severe side effects of cyclosporin used in a patient with steroid resistant severe ulcerative colitis after undergoing emergency Caesarean section. We would like to report our experience of a pregnant patient with steroid resistant severe distal ulcerative colitis in whom remission was induced with cyclosporin. She delivered a healthy baby at 34 weeks. 
A 36 year old woman presented for the first time with a five week history of bloody diarrhoea and mucus discharge in the 12th week of her first pregnancy. Ulcerative colitis was confirmed on flexible sigmoidoscopy and histology. She was started on mesalazine (Pentasa) $1 \mathrm{~g}$ twice daily orally and Pentasa enema was added subsequently. She failed to respond well to oral prednisolone $(40-60 \mathrm{mg}$ daily) for five weeks or to subsequent intravenous prednisolone given for a further two and a half weeks. Azathioprine (oral $150 \mathrm{mg}$ daily) was also added. Repeat sigmoidoscopy confirmed severe distal colitis with ulceration. At the $23 \mathrm{rd}$ week of pregnancy, she was started on intravenous cyclosporin $(2 \mathrm{mg} / \mathrm{kg})$ with careful monitoring of serum levels. Significant improvement was noted in two weeks, after which cyclosporin was changed to the oral route. Steroids were gradually tapered to $2.5 \mathrm{mg}$ daily. At 34 weeks she underwent an emergency Caesarean section because of antepartum haemorrhage and a healthy baby girl (birth weight $2.07 \mathrm{~kg}$ ) was delivered. Two weeks later, cyclosporin was weaned off after minimal rise of serum creatinine that coincided with high serum cyclosporin levels. Her serum creatinine normalised four weeks later. She and baby remained well on azathioprine and mesalazine 14 weeks after delivery.

Intravenous cyclosporin induced remission in our pregnant patient who had failed to respond to high dose oral and intravenous prednisolone. Colectomy and the associated potential complications in pregnancy were avoided. There is only one other case report in the literature ${ }^{1}$ where cyclosporin was used in similar circumstances. While we would agree that cyclosporin should be used cautiously in pregnancy, our positive experience, and that of Bertschinger and colleagues, ${ }^{1}$ suggests that cyclosporin may induce remission and avoid colectomy during pregnancy.

A Jayaprakash, S Gould, A G Lim Department of Gastroenterology, Epsom General Hospital, Epsom, Surrey, UK

H A Shehato

Department of Obstetric Medicine, Epsom General Hospital, Epsom, Surrey, UK

Correspondence to: $\operatorname{Dr}$ A Jayaprakash, 130 Farriers Road, Epsom KT17 1NS, UK; jaypy@hotmail.com

\section{Reference}

1 Bertschinger $\mathbf{P}$, Himmelmann A, Risti $B$, et al Ciclosporin treatment of severe ulcerative colitis during pregnancy. Am J Gastroenterol 1994;89:931-3.

\section{Is symptom control the correct end point for proton pump inhibitor treatment in Barrett's oesophagus?}

We have recently reported that abnormal acid reflux persists in up to $50 \%$ of patients with long segment Barrett's oesophagus, despite good control of symptoms of gastro-oesophageal reflux disease (GORD) with proton pump inhibitor (PPI) therapy. ${ }^{1}$ The critical question is whether such persistence of abnormal acid reflux alters the risk of progression to adenocarcinoma. We investigated this issue by studying cellular proliferation and expression of cyclin Dl, which is an important marker of neoplastic progression, ${ }^{23}$ in patients with Barrett's oesophagus on PPI therapy.

A prospective cross-sectional survey of 20 patients with long segment Barrett's oesophagus (defined as a length $\geqslant 3 \mathrm{~cm}$ and presence of specialised intestinal epithelium containing alcian blue staining goblet cells) was conducted. In all cases, GORD symptoms had been well controlled with PPI therapy (omeprazole $\mathrm{n}=13$ patients, median dose $20 \mathrm{mg}$ (range 10-40); lansoprazole $\mathrm{n}=5$, $30 \mathrm{mg}$; or rabeprazole $\mathrm{n}=2,20 \mathrm{mg}$ ). Patients had received PPI therapy for a median duration of 30 months (12-66). Oesophageal manometry, 24 hour ambulatory pHmetry, and Bilitec 2000 monitoring were conducted on all patients, without interruption of their usual PPI therapy. Representative endoscopic biopsy specimens of Barrett's oesophagus from each patient were studied for expression of cyclin Dl protein (primary antibody 1:50 dilution; Novocastra Lab) and Ki-67 protein (primary antibody 1:75; Dako Lab), by standard immunohistochemistry. The histopathologist was blinded to clinical information. A proliferative index was computed for each patient by scoring the percentage of Ki-67 labelled specialised columnar epithelial cells, as previously described. ${ }^{4}$ Cyclin Dl expression was semi quantitatively assessed. The mean percentage of positive cells in areas of intestinal-type specialised columnar epithelium was assigned to one of three categories: $0,<5 \%$; $1,5-50 \%$; or $2,>50 \%$. The intensity of cyclin Dl immunostaining was scored as: weak $=1$, moderate $=2$, or intense $=3$. The percentage category of positive cells and staining intensity were multiplied to produce a weighted score for each patient. All cases with weighted scores $\geqslant 1$ were designated positive.

Despite PPI therapy and absence of GORD symptoms, pHmetry detected abnormal acid
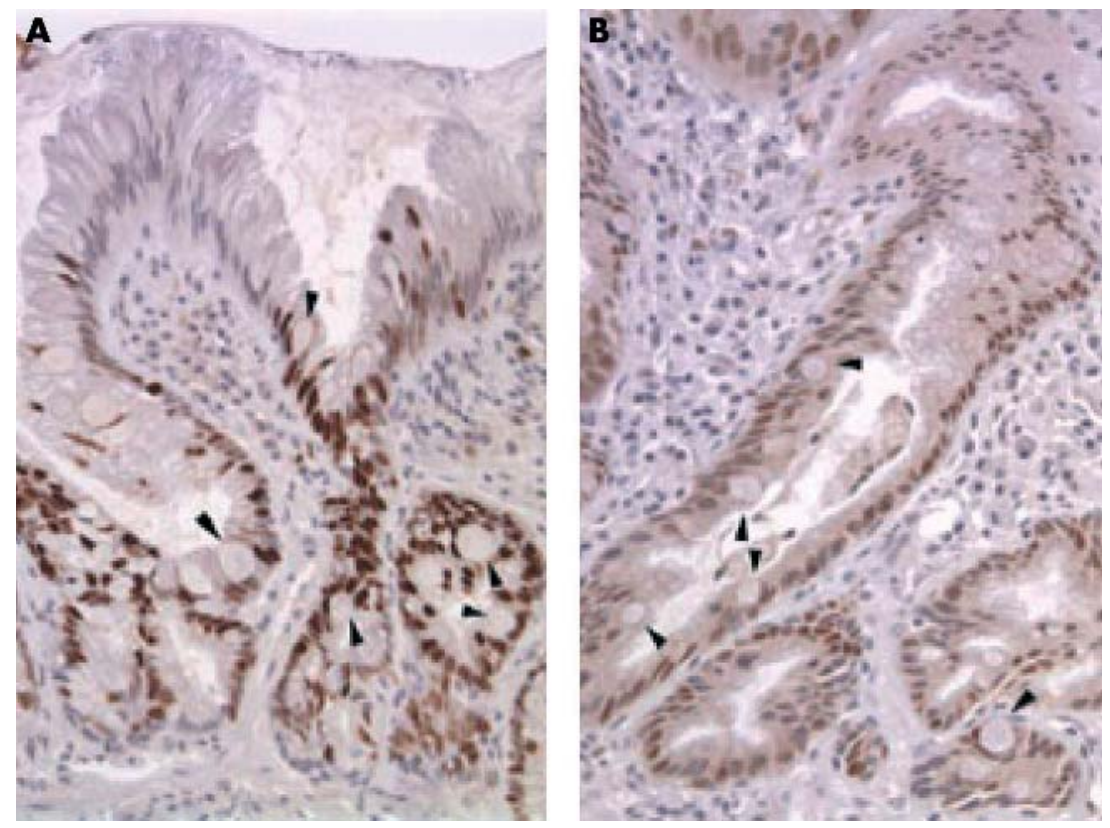

Figure 1 (A) Ki-67 immunoreactive cells are localised at the base of the crypts and glandular zones in specialised intestinal-type columnar epithelium. Arrowheads indicate some goblet cells (original magnification $200 \times$ ). (B) Specialised intestinal-type columnar epithelium exhibits moderate nuclear cyclin DI staining in the majority of epithelial cells lining the crypts (weighted score 4). Arrowheads indicate some goblet cells (original magnification $200 \times$ ). reflux in nine $(45 \%)$ patients $(\mathrm{pH}<4$ for (median) $19.2 \%$ (range $4.6-32.1$ ) of 24 hours DeMeester score 49.5 (20.2-109.8)). The the normal range $(\mathrm{pH}<4$ for $\leqslant 4.5 \%$ of 24 hours). Proliferative indices (mean (SD)) for patients with abnormal acid reflux and those with normal acid reflux were similar (36.5 (8.7) v 37.4 (5.5), respectively; $\mathrm{p}=0.3$ ). Cyclin Dl expression was positive in seven $(78 \%)$ patients with abnormal acid reflux and (64\%) patients with normal aci ( (range 2-6)) for patients with abnormal acid reflux and those with normal acid reflux.

These data imply that the risk of neoplastic progression was independent of the status of examined the association between acid reflux and bile reflux. Absorbance $\geqslant 0.14$ for $\leqslant 1.8 \%$ sidered the normal this study. Despite PPI therapy, abnormal bile reflux was detected in $12(60 \%)$ patients, including six $(55 \%)$ with normal acid reflux six $(66 \%)$ with abnormal acid reflux (absorbance $\geqslant 0.14$ for $17.4 \%$ (3.5-63.7)). Such persistent bile reflux may explain the similarity in expression of Ki-67 or cyclin Dl in the two groups with different control of acid eflux.

In contrast with PPI therapy, antireflux surgery that is successful in controlling acid reflux also controls bile reflux ${ }^{5}$ Following indices in surface epithelial cells and crypts of Barrett's oesophagus are significantly lower compared with a failed procedure. ${ }^{6}$ In the light of the present data, we propose the need for a novel clinical trial of PPI therapy versus antireflux surgery. Patients who are randomised to PPI therapy should undergo control of acid reflux by PPI therapy. We also 
serial $\mathrm{pH}$ and Bilitec monitoring, with appropriate therapeutic modification to achieve predetermined end points. Patients who are randomised to laparoscopic fundoplication should have additional PPI therapy, as required, to achieve the same end points. Outcomes should be measured by standard serial endoscopic assessment and also by examination of a panel of molecular and cellular markers that is important in the pathogenesis of Barrett's adenocarcinoma.

A I Sarela, C S Verbeke, C Pring, P J Guillou University of Leeds School of Medicine, Leeds, UK

Correspondence to: Mr A Sarela, B 37, Clarendon Wing, Department of Surgery, The General Infirmary at Leeds, Leeds LS1 3EX, UK; a.sarela@leeds.ac.uk

\section{References}

1 Sarela Al, Hick DG, Verbeke CS, et al. Persistent acid and bile reflux in asymptomatic patients with Barrett's esophagus on proton pump inhibitor therapy. Arch Surg 2004 (in press).

2 Bani-Hani K, Martin IG, Hardie U, et al. Prospective study of cyclin DI overexpression in Barrett's esophagus: association with increased risk of adenocarcinoma. J Natl Cancer Inst 2000;92:1316-21.

3 Gimenez A, Minguela A, de Haro LM, et al. DNA ploidy status and proliferative activity as markers of malignant potential in Barrett's esophagus: flow cytometric study using routinely paraffinembedded tissue. World J Surg 2000;24:72-7.

4 Sarela Al, Verbeke CS, Ramsdale J, et al. Expression of survivin, a novel inhibitor of apoptosis and cell cycle regulatory protein, in pancreatic adenocarcinoma. $\mathrm{Br} J$ Cancer 2002;86:886-92

5 Stein HJ, Kaver WK, Feussner $\mathrm{H}$, et al. Bile reflux in benign and malignant Barrett's esophagus: effect of medical acid suppression and nissen fundoplication. J Gastrointest Surg 1998:2:333-41.

6 Chen LQ, Hu CY, Gaboury L, et al. Proliferative activity in Barrett's esophagus before and after antireflux surgery. Ann Surg 2001;234:172-80.

\section{Improving hepatitis $\mathrm{C}$ services across the UK: response to a walk-in HCV testing service}

The Department of Health (DH) estimates that approximately $0.4 \%$ of the UK population are chronically infected with hepatitis C virus (HCV) (that is, 200000 people). As few as $10 \%$ of these individuals, who are at risk of end stage liver disease, are thought to be aware of their infection. Clearly action is required to identify and treat these patients with current drugs (pegylated interferons and ribavirin) that can cure over $50 \%$ of infected patients.

The UK voluntary sector have responded to the government identified need for more public information about HCV by organising a hepatitis C awareness day. We took advantage of the publicity around hepatitis $\mathrm{C}$ awareness day to assess the value of a walk-in HCV testing clinic.

Our clinic was held over four days (4-7 July 2003) and was widely publicised in the local press and television. Patients who wished to be tested were invited to attend a clinic in the Minor Injuries Unit at St Bartholomew's Hospital in the City of London. The clinic was manned between $8 \mathrm{am}$ until $1 \mathrm{lam}$ for counselling and informed testing (hepatitis C antibody test and liver function tests). Results were available the next day and patients were informed in person 24 hours later.
Nineteen people attended and two were infected. One of these patients had been lost to follow up due to non-attendance at a local liver clinic 12 years ago.

Open access confidential hepatitis $\mathrm{C}$ testing clinics may play an important role in encouraging people to come forward for HCV testing and may facilitate public education about this important treatable infection. However, these clinics are labour intensive and, in our experience, unlikely to provide a cost effective solution to the identification of people with this treatable, sometimes fatal, infection.

R F C D'Souza, M J Glynn, E Alstead, G R Foster Hepatobiliary Group, Barts and The London, Queen Mary's School of Medicine and Dentistry, London, UK

I Ushiro-Lumb

Department of Virology, Barts and The London, Queen Mary's School of Medicine and Dentistry, London, UK

Correspondence to: Professor G R Foster Hepatobiliary Group, Department of Gastroenterology, DDRC, Turner St, London El 2AD UK; g.r.foster@qmul.ac.uk

Conflict of interest: Dr Foster acts as a consultant to companies who sell drugs for the treatment of viral hepatitis and has received research funding from such companies. He has received fees from companies who market antiviral therapeutics.

\section{Influence of mode of delivery on gut microbiota composition in seven year old children}

Intestinal microbiota development begins immediately following birth. ${ }^{1}$ The composition of the infant's evolving microbiota is initially defined by the mother, the source of the newborn's first microbial inoculum. Colonising bacteria rapidly adapt to breast milk and epithelial mucins as sources of nutrients.

The prevalence of caesarean section delivery in Western countries is increasing. Caesarean born babies are deprived of contact with the maternal/vaginal microbiota and the first exposure is characterised by a lack of strict anaerobes and the presence of facultative anaerobes such as Clostridium species. ${ }^{2}$ Caesarean born infants have a more slowly diversifying microbiota, with differences reported from normally born infants, even after six months of age. Aberrancies in early microbiota acquisition can affect immunophysiological development with a heightened disease risk. ${ }^{23}$ This study assessed microbiota composition in seven year old children and compared the respective effects of normal delivery and caesarean section.

Table 1 Numbers of faecal bacteria (log 10 number of bacteria/g faeces) and total serum $\lg E$ concentration, and number of children with asthma or atopic dermatitis among seven year old children with a history of normal birth or caesarean section

\begin{tabular}{lccl}
\hline $\begin{array}{l}\text { Parameter (concn of specific microbe } \\
\text { or total lgE) }\end{array}$ & Normally delivered & Caesarean born & p Value \\
\hline Clostridia & $9.29(9.06-9.51)$ & $8.83(8.6-9.06)$ & 0.0055 \\
Bifidobacteria & $10.32(10.13-10.5)$ & $10.29(9.99-10.59)$ & 0.87 \\
Total bacteria & $11.56(11.46-11.7)$ & $11.59(11.5-11.68)$ & 0.61 \\
Lactobacilli/enterococci & $9.07(8.85-9.3)$ & $9.05(8.86-9.2)$ & 0.85 \\
Bacteroides & $9.95(9.67-10.24)$ & $9.84(9.52-10.17)$ & 0.63 \\
Total lgE & $79(16-255)$ & $65(25-160)$ & 0.85 \\
\hline
\end{tabular}

Values are median (interquartile range).
In all, 60 seven year old children were randomly selected from Southwestern Finland, representing caesarean and vaginal deliveries. ${ }^{4}$ The children were invited to attend a clinical examination, including skin prick testing and determination of serum total and antigen specific IgE antibodies. Perinatal data were derived from hospital medical records. Questionnaires were completed by the parents to verify a history of allergic symptoms.

Faecal samples were produced at clinical examination and frozen at $-70^{\circ} \mathrm{C}$ for microbiota assessment. Faecal microbiota profiles were determined using the culture independent fluorescent in situ hybridisation method. Probes specific for bifidobacteria, lactobacilli/enterococci, bacteroides, clostridia, and total bacterial numbers were applied. ${ }^{5}$ Written informed consent was obtained from parents and the study was approved by the ethics committee of the university.

Of the study population, 31 children had been delivered by caesarean section and 29 by vaginal delivery. At seven years of age, significantly higher numbers of clostridia were found in children delivered vaginally compared with caesarean born children $(\mathrm{p}=0.0055) \quad($ table 1$)$. No differences were observed in other faecal bacteria or total numbers of bacteria (table 1 ).

Children with asthma diagnosed by a physician $(n=6)$ had lower numbers of clostridia in their faecal specimens while healthy children $(n=54)$ had higher clostridial numbers.

Early colonisation guides subsequent microbiota development which may later impact on health, to the extent of predisposing some infants towards specific diseases. ${ }^{3}$ Bifidobacteria are considered useful for health promotion. Reported effects are related to the individual "balance" of the gut microbiota and prevention of aberrancies within the gastrointestinal tract. Clostridia are generally considered harmful toxin producing species causing diarrhoea and food poisoning.

Our results show that bifidobacterial levels in the faeces of cohort children were comparable at seven years of age, independent of the mode of delivery at birth, while numbers of clostridia were significantly higher in normally born children seven years after birth.

Differences in neonatal gut microbiota, in particular the balance between Bifidobacterium species and Clostridium species, have been reported to precede heightened production of antigen specific IgE antibodies, a hallmark of the atopic responder type. ${ }^{1}$ Such differences may be related to external environmental 
factors (for example, mode of delivery and early feeding practices). The results of this study, showing that clostridial numbers in normally born children seven years after delivery are significantly higher than in caesarean born children, demonstrate that abnormal development of the intestinal microbiota reported following caesarean section delivery may continue even beyond infancy. These findings call for further assessment of microbiota composition throughout childhood when dietary interventions may still offer a rational means of health improvement. It is of importance to characterise the optimal clostridial numbers and species composition at different ages following normal and caesarean delivery.

S Salminen

Department of Biochemistry, University of Turku 20014 Turku, Finland

G R Gibson, A L McCartney

Food Microbial Sciences Unit, School of Food Biosciences, University of Reading, Reading, UK

E Isolauri

Department of Paediatrics, University of Turku, 20014 Turku, Finland

Correspondence to: Professor S Salminen, Functional Foods Forum, University of Turku, 20014 Turku Finland; seppo.salminen@utu.fi

\section{References}

1 Guarner F, Malagelada J-R. Gut flora in health and disease. Lancet 2003:360:512-19.

2 Grönlund MM, Lehtonen OP, Eerola E, et al. Fecal microflora in healthy infants born by different methods of delivery: permanent changes in intestinal flora after Cesarean delivery. J Pediatr Gastroenterol Nutr 1999;28:19-25.

3 Kalliomäki M, Kirjavainen P, Eerola E, et al. Distinct patterns of neonatal gut microflora in infants developing or not developing atopy. $J$ Allergy Clin Immunol 2001;107:129-34.

4 Kero J, Gissler M, Grönlund MM, et al. Mode of delivery and asthma-is there a connection? Pediatr Res 2002; 52:6-11.

5 Kirjavainen PV, Arvola T, Salminen SJ, et al. Aberrant composition of gut microbiota of allergic infants: a target of bifidobacterial therapy at weaning? Gut 2002;51:51-5.

\section{Crohn's ileitis after liver transplantation from a living related donor with Crohn's disease}

We read with interest the case described by Sonwalkar et al of a patient who developed fulminant Crohn's colitis after allogeneic stem cell transplantation (ASCT) (Gut 2003;52:1518-21). Although the donor had no known Crohn's disease (CD) and did not carry the IBD3 or IBD5 haplotypes associated with CD, HLA class III mismatches at IBD3 and a CD associated polymorphism of the 5'UTR of NOD2/CARD15 were present in the donor and in the reconstituted immune cell population of the recipient post ASCT. The authors hypothesised that adoptive transfer of CD susceptibility may have occurred between ACST donor and recipient.

Herein, we report a case of a patient who developed CD after receiving a living related liver transplant from a donor with known CD. A 24 year old female received a liver transplant from a living related donor for decompensated cirrhosis secondary to vertically transmitted chronic hepatitis C infection. The family history was significant for a

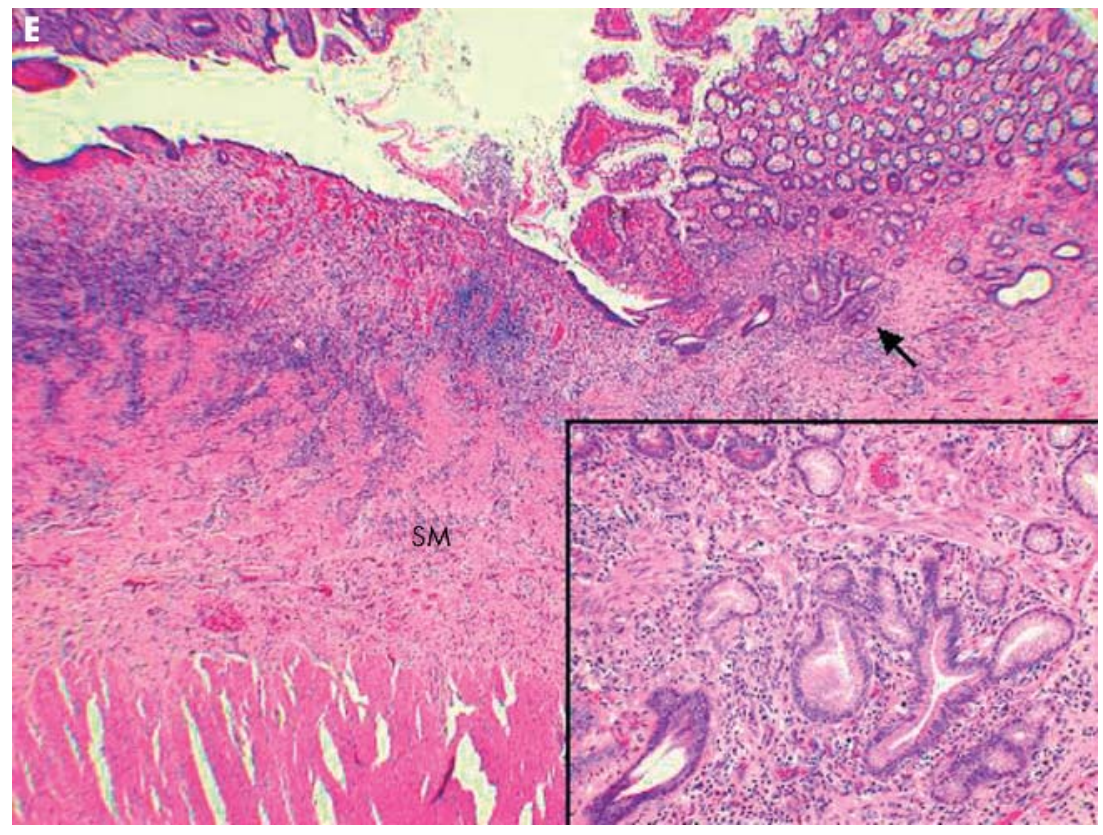

Figure 1 Histopathological examination of a resected ileal specimen demonstrated focal villous blunting, expansion of the lamina propria with acute and chronic inflammatory cells, reactive crypt changes, and occasional crypt abscesses and focal gastric metaplasia (arrow and insert). SM, submucosa.

maternal aunt diagnosed with $\mathrm{CD}$, who served as the liver donor, and a maternal uncle and grandfather with colon cancer. Following liver transplantation, the patient was maintained on an immunosuppressive regimen consisting of tacrolimus $3 \mathrm{mg}$ twice daily, sirolimus $5 \mathrm{mg}$ daily, as well as TMPSMZ prophylaxis. Her initial post-transplant course was uneventful but she later developed recurrent hepatitis C infection, treated with pegylated interferon and ribavirin. She presented with symptoms consistent with intermittent small bowel obstruction 11 months post-transplant. She was also receiving prednisone $15 \mathrm{mg}$ daily at that time. A computed tomography scan of the abdomen and pelvis (see fig lA on the Gut website: www.gutjnl.com) and an upper gastrointestinal with small bowel follow through study (see fig 1B on the Gut website: www.gutjnl.com) demonstrated marked fold thickening of the distal ileum. An enteroscopy demonstrated patchy ulcerations in the jejunum and Roux-en-Y limb of the small bowel. Biopsies showed focal ulceration and mild active inflammation without evidence of granuloma or viral inclusions. Wireless capsule endoscopy demonstrated multiple erosive and ulcerative changes in the distal small intestine (see fig IC, ID on the Gut website: www.gutjnl.com).

Because of persistent symptoms and concern for possible lymphoproliferative disorder, the patient underwent an open laparoscopy which revealed nodularity of the terminal ileum. Intraoperative colonoscopy demonstrated nodularity and three ulcers in the distal ileum. Histopathological examination of the resected ileal specimen demonstrated focal villous blunting, expansion of the lamina propria with acute and chronic inflammatory cells, reactive crypt changes, and occasional crypt abscesses and focal gastric metaplasia (see fig $\mathrm{lE}$, arrow and insert below). Mucosal ulcerations were underlined by inflamed granulation tissue containing occasional histiocytes and multinucleated giant cells. The submucosa also showed intense fibrosis and hyperplasia of the nerve bundles (not shown).

Few cases of de novo IBD developing after liver transplantation for chronic liver disease other than primary sclerosing cholangitis have been described. ${ }^{1-4}$ We present a case of $\mathrm{CD}$ developing in the recipient of a liver transplant from a living related donor with a known history of $\mathrm{CD}$. The recipient tested negative for any of the three common $C D$ associated NOD2/CARD15 variants (R702W, G908R, 1007fsinsC) but unfortunately we were unable to screen the liver donor for these polymorphisms. Our case, similar to that described by Sonwalkar et al, raises the intriguing possibility that $\mathrm{CD}$ susceptibility may have been transferred to the recipient with liver transplantation as well. Collins et a have reported complete and stable replacement of recipient haematopoiesis and $\mathrm{B}$ lymphopoiesis with donor derived cells approximately six weeks following orthotopic liver transplantation for haemochromatosis. $\mathrm{T}$ lineage reconstitution also occurred and derived almost exclusively from expansion of mature memory/effector $\mathrm{T}$ cells from the transplanted liver. One possibility is that the expanded immune cells have become tolerant to the graft but not to the intestinal luminal antigens leading to the development of CD. Whether liver donor selection should exclude those with a known diagnosis of $\mathrm{CD}$ is unclear and is still premature to answer.

K A Papadakis, R Matuk, M T Abreu, E A Vasiliauskas, P R Fleshner, J Lechago, T Tran, F F Poordad, P Martin, J Vierling, S R Targan

Cedars-Sinai Medical Center, UCLA School of Medicine, Los Angeles, California, USA 

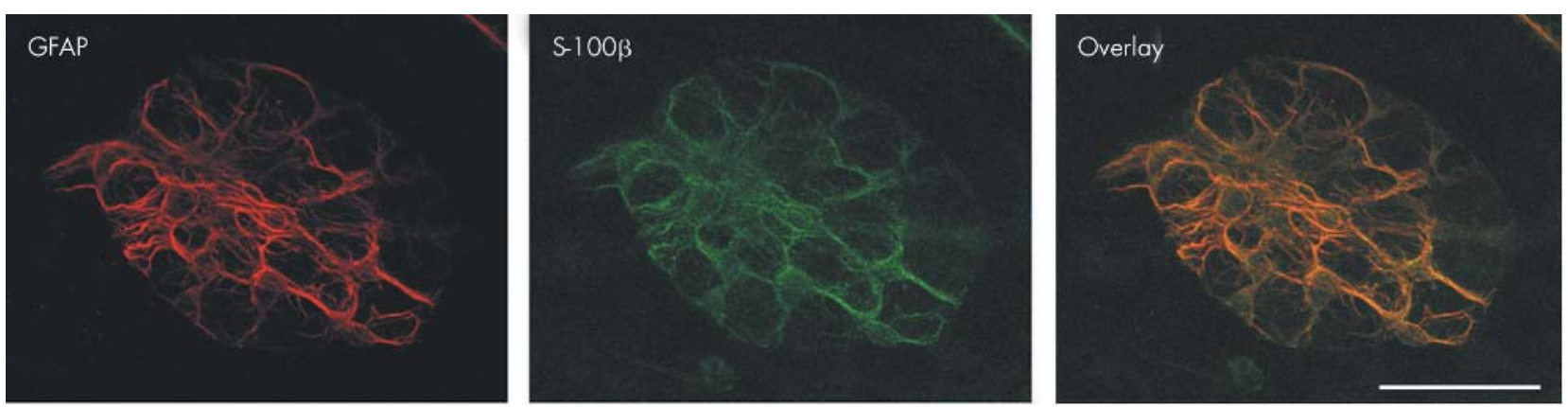

Figure 1 Confocal image revealing colocalisation of glial fibrillary acidic protein (GFAP) and S-100 in enteric glia.

Correspondence to: Dr K A Papadakis, Cedars-Sinai Medical Center, UCLA School of Medicine, 8700 Beverly Blvd, D-4063 Los Angeles, California 90048 , USA; Papadakisk@cshs.org

\section{References}

1 Passfall J, Distler A, Riecken EO, et al. Development of ulcerative colitis under the immunosuppressive effect of cyclosporine. Clin Invest 1992;70:611-13.

2 Riley TR, Schoen RE, Lee RG, et al. A case series of transplant recipients who despite immunosuppression developed inflammatory bowel disease. Am J Gastroenterol 1997:92:279-82.

3 Cuoco L, Tursi A, Cammarota G, et al. Onset of ulcerative colitis during immunosuppressive therapy for liver transplantation. Am $J$ Gastroenterol 1997;92:2134-5.

4 Ramii A, Owen DA, Erb SR, et al. Post-liver transplant Crohn's disease: graft tolerance but not self-tolerance? Digest Dis Sci 2002;47:522-7.

5 Collins RH jr, Sackler M, Pitcher CJ, et al. Immune reconstitution with donor-derived memory/ effector T cells after orthotopic liver transplantation. Exp Hematol 1997;25: 147-59.

\section{Enteric glia}

von Boyen et al recently reported a study of glial fibrillary acidic protein (GFAP) expression in enteric glia (Gut 2004;53;222-8). Their new data are very interesting and add to our understanding of the possible role of enteric glia in gastrointestinal pathophysiology. However, we must take issue with some of the data presented that show extensive nuclear labelling with S-100 and with the description of the distribution of enteric glia in the colon.

Figure 1 of their paper shows labelling of enteric glia in the rat colon below the epithelial crypts and is thus presumably labelling of cells in the submucosal plexus. In the paper, this layer is described as the "plexus mucosus". The plexus mucosus, which is also known as the mucosal plexus, ${ }^{1}$ has previously been described in humans and rat. $^{23}$ As the name implies, the mucosal plexus is located within the mucosa. Given the position of the crypts, as indicated by the ovals in fig 1 , it would appear that the labelling shown in panels $A$ and $B$ is in fact localised to the submucosal plexus.

We find extensive colocalisation of GFAP and S-100 in the submucosal plexus. This is illustrated below in fig 1 in a whole mount preparation of the submucosal plexus from the rat colon. This confocal image reveals colocalisation of GFAP and S-100 in enteric glia ( $17 \mu \mathrm{m} \mathrm{z}$ stack of $1 \mu \mathrm{m}$ optical sections; scale bar $50 \mu \mathrm{m}$ ) (fig 1). S-100 is also found in the cytoplasm of the glial perikarya; there is virtually no nuclear labelling, which was the most obvious element of the staining demonstrated by von Boyen et al.

In fig 1 of the paper of von Boyen et al, the nature of the GFAP immunoreactivity is not fibrous, but granular, while the predominant labelling of S-100 is nuclear. In our hands this is not the case (see our fig 1) and so we feel this calls into question whether the extensive nuclear labelling observed in both fig 1 and fig 2 is really reflective of the distribution of S-100. Moreover, in the paper cited by the authors in support of nuclear localisation, Ferri et al state that "only cytoplasmic localisation (of S-100) was consistently demonstrated in enteric glia", ${ }^{4}$ contrary to von Boyen et al's assertion that S-100 labelling is largely nuclear.

Finally, it should also be noted that GFAP expression in culture may reflect an altered state of differentiation as an adaptation to culturing. ${ }^{56}$ Hence some of the observed changes in GFAP expression may be explained by processes reflecting changes in the culture conditions rather than a pathophysiological response to cytokines.

The issues of glial heterogeneity and the role of enteric glia in inflammation raised in the paper are very interesting, and of considerable importance in understanding the physiology and pathophysiology of the gastrointestinal tract. By analogy with the brain, it is likely that enteric glia play an important role in the function of the gut. However, we feel that the extensive glial heterogeneity suggested in the paper by von Boyen et al may be overestimated and we urge caution in extrapolation of these data based on the immunohistochemistry presented in this manuscript.

K A Sharkey, Y Nasser Gastrointestinal Research Group, Department of Physiology and Biophysics, University of Calgary, Calgary, Alberta, Canada

A Ruhl

Department of Human Biology, Technical University Munich, Freising-Weihenstephan, Germany

Correspondence to: Professor K A Sharkey, Gastrointestinal Research Group, Department of Physiology and Biophysics, University of Calgary, 3330 Hospital Drive, NW Calgary, Alberta, Canada T2N 4N1; ksharkey@ucalgary.ca

\section{References}

Furness JB, Costa M. The enteric nervous system. Edinburgh: Churchill-Livingstone, 1987.

2 Wedel T, Roblick U, Gleiss J, et al. Organization of the enteric nervous system in the human colon demonstrated by wholemount immunohistochemistry with special reference to the submucous plexus. Anat Anz 1999; 181:327-37.

3 Stach W. Innervation of the small intestinal mucosa of laboratory animals. II. Ultrastructure of neuro-cellular connections. Z Mikrosk Anat Forsch 1979:93:1012-24.

4 Ferri GL, Probert L, Cocchia D, et al. Evidence for the presence of S-100 protein in the glial component of the human enteric nervous system. Nature 1982;297:409-10.

5 Juurlink BH, Hertz L. Plasticity of astrocytes in primary cultures: an experimental tool and a reason for methodological caution. Dev Neurosci 1985;7:263-77.

6 Hauck SM, Suppmann S, Ueffing M. Proteomic profiling of primary retinal Müller glia cells reveals a shift in expression patterns upon adaptation to in vitro conditions. Glia 2003;44:251-63.

\section{CORRECTIONS}

doi: 10.1136/gut.2003.021154corrl

In the paper by Wang et al (Gut 2004;53:1096-1101), the acknowledgement and correct email address were not presented. The acknowledgement should have read as follows: "The authors thank senior technician Shu-Hao Wen for her assistance in processing the tissue slides, and Drs Jian-Ming Qian, Gang Sun, and Xiao-Hong Liu for their help in collecting the biopsy samples for the study project." In addition, the correct email address for Professor G-Z Pan is: pgz@public3.bta.net.cn.

\section{doi: 10.1136/gut.2003.027425corr 1}

An author was omitted from the paper by Francés et al (Gut 2004;53:860-4), entitled Bacterial DNA activates cell mediated immune response and nitric oxide overproduction in peritoneal macrophages from patients with cirrhosis and ascites. This paper was published in the June issue and the missing author is E Rodriguez, Immunology Department, Hospital General Universitario, Alicante, Spain. 